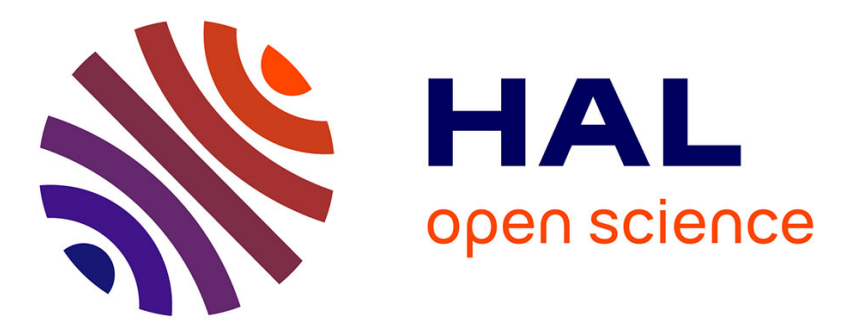

\title{
An approximate Riemann solver for second-moment closures
}

Gilles Brun, Jean-Marc Hérard, Denis Jeandel, Markus Uhlmann

\section{To cite this version:}

Gilles Brun, Jean-Marc Hérard, Denis Jeandel, Markus Uhlmann. An approximate Riemann solver for second-moment closures. Journal of Computational Physics, 1999, 151 (2), pp.990-996. 10.1006/jcph.1999.6190 . hal-01579989

\section{HAL Id: hal-01579989 \\ https://hal.science/hal-01579989}

Submitted on 8 Jan 2020

HAL is a multi-disciplinary open access archive for the deposit and dissemination of scientific research documents, whether they are published or not. The documents may come from teaching and research institutions in France or abroad, or from public or private research centers.
L'archive ouverte pluridisciplinaire HAL, est destinée au dépôt et à la diffusion de documents scientifiques de niveau recherche, publiés ou non, émanant des établissements d'enseignement et de recherche français ou étrangers, des laboratoires publics ou privés. 


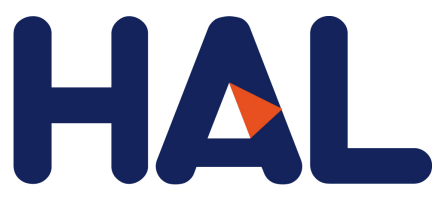

archives-ouvertes

\title{
An approximate Riemann solver for second-moment closures
}

\author{
Gilles Brun, Jean-Marc Hérard, Denis Jeandel, Markus Uhlmann
}

\section{To cite this version:}

Gilles Brun, Jean-Marc Hérard, Denis Jeandel, Markus Uhlmann. An approximate Riemann solver for second-moment closures. Journal of Computational Physics, Elsevier, 1999, 151 (2), pp.990-996. hal-01579989

\section{HAL Id: hal-01579989 \\ https://hal.archives-ouvertes.fr/hal-01579989}

Submitted on 8 Jan 2020

HAL is a multi-disciplinary open access archive for the deposit and dissemination of scientific research documents, whether they are published or not. The documents may come from teaching and research institutions in France or abroad, or from public or private research centers.
L'archive ouverte pluridisciplinaire HAL, est destinée au dépôt et à la diffusion de documents scientifiques de niveau recherche, publiés ou non, émanant des établissements d'enseignement et de recherche français ou étrangers, des laboratoires publics ou privés. 


\title{
NOTE
}

\section{An Approximate Riemann Solver for Second-Moment Closures}

\author{
G. Brun, * J.-M. Hérard, † D. Jeandel,ł and M. Uhlmann $\ddagger$ \\ * Société METRAFLU, 64, chemin des Mouilles, 69134 Ecully Cedex, France; †DER-LNH, Electricité de \\ France, 6, quai Watier, 78400 Chatou Cedex, France; and $\ddagger L M F A$, UMR 5509, Ecole \\ Centrale de Lyon, 36, avenue Guy de Collongue, 69131 Ecully Cedex, France \\ E-mail: brun@mecaflu.ec-lyon.fr, Jean-Marc.Herard@der.edf.fr, \\ jeandel@mecaflu.ec-lyon.fr, uhlmann@torroja.dmt.upm.es
}

Received February 18, 1998; revised January 4, 1999

\section{THE BASIC SYSTEM OF NON-CONSERVATIVE EQUATIONS}

The hyperbolic convective subset of a second-moment turbulence closure for the Favreaveraged compressible Navier-Stokes equations can be written as [1]

$$
\begin{aligned}
(\rho)_{, t}+\left(\rho U_{j}\right)_{, j} & =0 \\
\left(\rho U_{i}\right)_{, t}+\left(\rho U_{i} U_{j}+\delta_{i j} p+\rho R_{i j}\right)_{, j} & =0 \\
(\rho E)_{, t}+\left(\rho E U_{j}+U_{i}\left(p \delta_{i j}+\rho R_{i j}\right)\right)_{, j} & =0 \\
\left(\rho R_{i j}\right)_{, t}+\left(\rho R_{i j} U_{k}\right)_{, k} & =-\rho R_{i k} U_{j, k}-\rho R_{j k} U_{i, k},
\end{aligned}
$$

where $\rho$ stands for the mean density, $\mathbf{U}$ is the density weighted mean velocity vector, $\mathbf{R}$ the Reynolds stress tensor with components $R_{i j}=\widehat{u_{i}^{\prime \prime} u_{j}^{\prime \prime}}, E$ the mean specific total energy, and $p$ the mean pressure which can be expressed via the ideal gas law (with $\gamma$ being the ratio of specific heats), viz.,

$$
p=(\gamma-1)\left(\rho E-\frac{1}{2} \rho U_{k} U_{k}-\frac{1}{2} \rho R_{k k}\right) .
$$

For simplicity we will restrict the following presentation to flows with statistically two space dimensions, i.e., a variable vector $\mathbf{W}=\left(\rho, \rho U, \rho V, \rho E, \rho R_{11}, \rho R_{22}, \rho R_{33}, \rho R_{12}\right)^{t}$, such that we can write the system in matrix-vector notation

$$
\mathbf{W}_{, t}+\left(\mathbf{F}_{i}(\mathbf{W})\right)_{, i}=\mathbf{H}(\mathbf{W}, \nabla \mathbf{W}), \quad i=1,2,
$$


and furthermore define the following projections with respect to coordinates $(\mathbf{n}, \tau, \mathbf{s})$,

$$
\begin{array}{lll}
U_{n}=\mathbf{U}^{t} \mathbf{n}, & R_{n n}=\mathbf{n}^{t} \mathbf{R} \mathbf{n}, & R_{n \tau}=\mathbf{n}^{t} \mathbf{R} \boldsymbol{\tau} \\
U_{\tau}=\mathbf{U}^{t} \boldsymbol{\tau}, & R_{\tau \tau}=\boldsymbol{\tau}^{t} \mathbf{R} \boldsymbol{\tau}, & R_{s s}=R_{33},
\end{array}
$$

where $\mathbf{n}=\left(n_{x}, n_{y}, 0\right), \tau=\left(-n_{y}, n_{x}, 0\right)$, and $\mathbf{s}=(0,0,1)$.

Equations (1) cannot be cast into conservation form due to the presence of turbulence production. The characteristics wave system has the following eigenvalues with respect to an arbitrary direction $\mathbf{n}$ :

$$
\begin{gathered}
\lambda_{1}=U_{n}-c_{1}, \quad \lambda_{2}=U_{n}-c_{2}, \quad \lambda_{3-6}=U_{n}, \quad \lambda_{7}=U_{n}+c_{2}, \\
\lambda_{8}=U_{n}+c_{1}, \quad c_{1}=\sqrt{\gamma p / \rho+3 R_{n n}}, \quad c_{2}=\sqrt{R_{n n}} .
\end{gathered}
$$

An approximate analytical solution to the Riemann problem of the above system has been obtained in [2] resorting to a linear path across genuinely non-linear waves. With these ingredients it is possible to construct a full Godunov scheme as has been successfully done in the related case of a $k-\varepsilon$ type closure [3]. In this note, we will alternatively present an approximate numerical Riemann solver. The basic flux-difference-splitting technique will be recalled first before moving on to the case of a non-conservative system.

\section{ROE'S SCHEME FOR SYSTEMS OF CONSERVATION LAWS}

Let us consider a hyperbolic system of one-dimensional conservation laws in twodimensional space (without summation over subscript $n$ ),

$$
\mathbf{W}_{, t}+\mathbf{A}_{n}^{\text {cons }}(\mathbf{W}, \mathbf{m}) \cdot \mathbb{W}_{, n}=0, \quad \mathbf{A}_{i}^{\text {cons }}=\frac{\partial \mathbf{F}_{i}}{\partial \mathbf{W}}
$$

where we define

$$
\mathbf{A}_{n}(\mathbf{W}, \mathbf{n})=n_{x} \cdot \mathbf{A}_{1}(\mathbf{W})+n_{y} \cdot \mathbf{A}_{2}(\mathbf{W}), \quad \mathbf{F}_{n}(\mathbf{W}, \mathbf{n})=n_{x} \cdot \mathbf{F}_{1}(\mathbf{W})+n_{y} \cdot \mathbb{F}_{2}(\mathbf{W})
$$

An approximate Riemann solver provides the exact solution to the linearized problem

$$
\mathbf{W}_{, t}+\mathcal{A}\left(\mathbf{W}_{L}, \mathbf{W}_{R}, \mathbf{n}\right) \cdot \mathbf{W}_{, n}=0
$$

which consists of five simple waves since all fields are linearly degenerate (note that the subscripts ()$_{L}$ and ()$_{R}$ indicate states to the left and right, respectively, of the the initial discontinuity traveling along the direction $\mathbf{n}$ ). The corresponding numerical flux function is thus expressed by the well-known formula

$$
\mathcal{F}^{R o e}=\frac{1}{2}\left(\mathbb{F}_{n}\left(\mathbf{W}_{L}, \mathbf{n}\right)+\mathbb{F}_{n}\left(\mathbf{W}_{R}, \mathbf{n}\right)\right)-\frac{1}{2}\left|\mathcal{A}\left(\mathbf{W}_{L}, \mathbf{W}_{R}, \mathbf{m}\right)\right| \cdot\left(\mathbf{W}_{R}-\mathbf{W}_{L}\right)
$$

The problem of finding a sensible linearization $\mathcal{A}\left(\mathbf{W}_{L}, \mathbf{W}_{R}, \mathbf{n}\right)$ has been translated into three conditions of consistency by Roe [4]: 
(i) $\mathcal{A}\left(\mathbf{W}_{L}, \mathbf{W}_{R}, \mathbf{n}\right)$ is hyperbolic and a diagonal form exists,

(ii) $\mathcal{A}(\mathbf{W}, \mathbf{W}, \mathbf{n})=\mathbf{A}_{n}^{\text {cons }}(\mathbf{W}, \mathbf{n})$,

(iii) $\mathcal{A}\left(\mathbf{W}_{L}, \mathbf{W}_{R}, \mathbf{n}\right)[\mathbf{W}]=\left[\mathbf{F}_{n}(\mathbf{W}, \mathbf{n})\right]$ (defining the jump $\left.[\phi]=\phi_{R}-\phi_{L}\right)$.

In the case of the Euler equations of gas dynamics, it turns out that the linearized system matrix is equal to the original system matrix under a transformation of variables that has been termed Roe's average:

$$
\mathcal{A}^{\text {Euler }}=\mathbf{A}^{\text {Euler }}\left(\mathbf{W}^{\text {Roe }}\left(\mathbf{W}_{L}, \mathbf{W}_{R}\right), \mathbf{n}\right)
$$

In the past, some authors have forced the hyperbolic part of the second-moment closure equations to take a conservative form by eliminating from Eq. (1) the production term and the action of the Reynolds stress in the conservative flux of momentum and total energy $[5,1]$. In the resulting truncated system turbulence is only felt via the pressure that is defined by Eq. (2). This simplified approach enables us to simply use Roe's flux formulation (9) in conjunction with Roe's average for all variables (cf. [1] for details). We will demonstrate below that this approach can give rise to unphysical solutions.

\section{ROE-TYPE SCHEME FOR NON-CONSERVATIVE SYSTEMS}

We return to our non-conservative system of transport equations

$$
\begin{gathered}
\mathbf{W}_{, t}+\mathbf{A}_{n}(\mathbf{W}, \mathbf{n}) \cdot \mathbf{W}_{, n}=0 \\
\text { where } \mathbf{A}_{i}=\frac{\partial \mathbf{F}_{i}}{\partial \mathbf{W}}+\mathbf{C}_{i}^{n c}(\mathbf{W}), \quad \mathbf{C}_{\mathbf{i}}^{\mathbf{n c}}(\mathbf{W}) \cdot \mathbf{W}_{, \mathbf{i}}=-\mathbf{H}(\mathbf{W}, \nabla \mathbf{W}) .
\end{gathered}
$$

$\Lambda$ s seen below, we discretize the source term $\mathbf{C}_{n}^{n c}(\mathbf{W}, \mathbf{n}) \mathbf{W}_{, n}$ in a simple, centered manner. As a consequence, applying Roe's flux-difference-splitting gives formally the same numerical flux formula as in the above case of conservation law [1]:

$$
\mathcal{F}^{R N C}=\frac{1}{2}\left(\mathbf{F}_{n}\left(\mathbf{W}_{L}, \mathbf{n}\right)+\mathbf{F}_{n}\left(\mathbf{W}_{R}, \mathbf{n}\right)\right)-\frac{1}{2}\left|\mathcal{A}\left(\mathbf{W}_{L}, \mathbf{W}_{R}, \mathbf{n}\right)\right| \cdot\left(\mathbf{W}_{R}-\mathbf{W}_{L}\right) .
$$

Similarly, we require the linearization $\mathcal{A}$ to fulfill the following two fundamental constraints:

(i) $\mathcal{A}\left(\mathbf{W}_{L}, \mathbf{W}_{R}, \mathbf{n}\right)$ is hyperbolic and a diagonal form exists,

(ii) $\mathcal{A}(\mathbf{W}, \mathbf{W}, \mathbf{n})=\mathbf{A}_{n}(\mathbf{W}, \mathbf{n})$.

In a straightforward extension of Roe's above idea (iii), i.e., that the numerical flux be exact in the case of a shock wave being located between two nodes, one would write as the third condition

$$
\text { (iii) })_{a} \mathcal{A}\left(\mathbf{W}_{L}, \mathbf{W}_{R}, \mathbf{n}\right)[\mathbf{W}]=\left[\mathbf{F}_{n}(\mathbf{W}, \mathbf{n})\right]+\overline{\mathbf{C}_{n}^{n c}}\left(\mathbf{W}_{L}, \mathbf{W}_{R}, \mathbf{n}\right)[\mathbf{W}] .
$$

The jump conditions of the non-conservative source term $\overline{\mathbf{C}_{n}^{n c}}\left(\mathbf{W}_{L}, \mathbf{W}_{R}, \mathbf{n}\right)[\mathbf{W}]$ are the approximate ones based on the assumption of a linear path in terms of the variable $\mathbf{Z}=$ $\left(1 / \rho, U, V, p, \rho R_{n n}, \rho R_{\tau \tau}, \rho R_{s s}, \rho R_{n \tau}\right)^{t}$. The proposition of a linear path is due to Le Floch [6] and has been put forth in the context of a generalized Rankine-Hugoniot condition for non-conservative hyperbolic systems (cf. also [7]). Our particular choice of the variable $\mathbf{Z}$ has been inspired by previous work on $k-\varepsilon$ type closures (cf. [8, 9, 3]). It leads to the desirable feature that the jump conditions (a) reduce to the exact Rankine-Hugoniot relations in the limit of zero turbulence, and that (b) are equivalent to the Riemann invariants in the 
case of linearly degenerate fields (cf. [1, 10,2]). However, we would like to emphasize that the condition (iii) $)_{a}$ is strictly valid only in the limit of zero shock strength and cannot be regarded as a rigorous consistency condition as in the case of conservative systems.

In the case of $k-\varepsilon$ type closures $[11,12]$ and in the context of two-phase flows [13], conditions (i), (ii), and (iii) ${ }_{a}$ again lead to a linearized matrix resembling the original system matrix

$$
\mathcal{A}\left(\mathbf{W}_{L}, \mathbf{W}_{R}, \mathbf{n}\right)=\mathbf{A}_{n}\left(\tilde{\mathbf{W}}\left(\mathbf{W}_{L}, \mathbf{W}_{R}\right), \mathbf{m}\right),
$$

where $\tilde{\mathbf{W}}$ is a particular average that differs from Roe's averaging.

In the present case, however, the linearized matrix $\mathcal{A}$ obtained from the above relations (i), (ii), and (iii) ${ }_{a}$ cannot be recast into the form of the system matrix $\mathbf{A}_{n}\left(\hat{\mathbf{W}}\left(\mathbf{W}_{L}, \mathbf{W}_{R}\right), \mathbf{n}\right)$ since a corresponding average $\hat{\mathbf{W}}$ does not exist [1]:

$$
\nexists \hat{\mathbf{W}}\left(\mathbf{W}_{L}, \mathbf{W}_{R}\right) / \mathbf{A}_{n}(\hat{\mathbf{W}}, n)[\mathbf{W}]=\left[\mathbf{F}_{n}(\mathbf{W}, \mathbf{n})\right]+\overline{\mathbf{C}_{n}^{n c}}\left(\mathbf{W}_{L}, \mathbf{W}_{R}, \mathbf{n}\right)[\mathbf{W}]
$$

The matrix $\mathcal{A}$ that issues from condition (iii) ${ }_{a}$ is thus in a form not suitable for numerical purposes, in particular its diagonalization could not be obtained. Alternatively, an approximate Godunov scheme can be constructed [10,2] which does not rely on Roe's condition (iii). In the same spirit, we have relaxed this condition and replaced it by the following simple expression based on an arithmetic average:

$$
\text { (iii) } \left._{b} \mathcal{A}\left(\mathbf{W}_{L}, \mathbf{W}_{R}, \mathbf{n}\right)=\mathbf{A}_{n}(\mathbf{W}(\overline{\mathbf{Y}}), \mathbf{n}) \text { (defining } \overline{\mathbf{Y}}=\left(\mathbf{Y}_{L}+\mathbf{Y}_{R}\right) / 2\right) \text {, }
$$

where $\mathbf{Y}=\left(\rho, U_{n}, U_{\tau}, H_{l}, R_{n n}, R_{\tau \tau}, R_{s s}, R_{n \tau}\right)^{t}$ in local coordinates $(\mathbf{n}, \tau$ perpendicular and tangential respectively to the discontinuity) and total enthaply being defined as $H_{t}=$ $E+p / \rho$. Our numerical flux function can finally be written as (RNC designating Roe non-conservative)

$$
\mathcal{F}^{R N C}=\frac{1}{2}\left(\mathbf{F}_{n}\left(\mathbf{W}_{L}, \mathbf{n}\right)+\mathbf{F}_{n}\left(\mathbf{W}_{R}, \mathbf{n}\right)\right)-\frac{1}{2}|\mathbf{A}(\mathbf{W}(\overline{\mathbf{Y}}), \mathbf{n})| \cdot\left(\mathbf{W}_{R}-\mathbf{W}_{L}\right)
$$

The "absolute value" of the system matrix is calculated through the relation

$$
|\mathbf{A}(\mathbf{W}(\overline{\mathbf{Y}}), \mathbf{n})|=\mathcal{R}(\mathbf{W}(\overline{\mathbf{Y}}), \mathbf{n}) \cdot|\Lambda(\mathbf{W}(\overline{\mathbf{Y}}), \mathbf{n})| \cdot \mathcal{R}^{-1}(\mathbf{W}(\overline{\mathbf{Y}}), \mathbf{n}),
$$

where $\Lambda$ is the diagonal eigenvalue matrix and $\mathcal{R}$ and $\mathcal{R}^{-1}$ the diagonalization matrices containing the right and left eigenvectors, respectively.

\section{INTEGRATION METHOD}

Since in most finite volume methods multidimensional flows are treated as a succession of quasi one-dimensional problems for each cell face, it suffices in the following to present a one-dimensional discretization.

Integrating Eq. (11) over a finite volume $\Omega_{i}$ ( $V_{\Omega_{i}}$ being the cell volume, $\Gamma_{i}$ designating the cell surface, $\Delta t$ the time step, superscript $n$ indexing time steps, $\mathbf{n}$ being the outward 
normal vector) we obtain

$$
V_{\Omega_{i}} \cdot\left(\mathbf{W}_{i}^{n+1}-\mathbf{W}_{i}^{n}\right)+\Delta t\left\{\oint_{\Gamma_{i}} \mathcal{F}^{R N C}\left(\mathbf{W}_{L}^{n}, \mathbf{W}_{R}^{n}, \mathbf{m}\right) \mathrm{d} \Gamma_{i}+\mathbb{S}_{i}\left(\mathbf{W}^{n}\right)\right\}=0 .
$$

The source terms $\mathbf{S}_{i}$ are expressed by a centered difference, so that

$$
\mathbf{S}_{i}=\int_{\Omega_{i}} \mathbb{C}^{n c}(\mathbf{W}) \cdot \mathbf{W}_{, n} \mathrm{~d} \Omega=\mathbb{C}^{n c}\left(\mathbf{W}_{i}^{n}\right) \cdot \int_{\Omega_{i}} \mathbf{W}_{, n} \mathrm{~d} \Omega=\mathbb{C}^{n c}\left(\mathbf{W}_{i}^{n}\right) \cdot \oint_{\Gamma_{i}} \mathcal{W}_{\Gamma}\left(\mathbf{W}^{n}\right) \mathrm{d} \Gamma_{i},
$$

where

$$
\mathcal{W}_{L R}\left(\mathbf{W}^{n}\right)=\frac{\mathbf{W}_{L}^{n}+\mathbf{W}_{R}^{n}}{2}
$$

at the respective cell face $L R$.

\section{QUASI ONE-DIMENSIONAL RIEMANN PROBLEMS}

The first case is a Sod [14] shock tube with high turbulence Mach numbers $\left(Y_{L}=(1,0,0\right.$, $\left.4.5 \cdot 10^{5}, \frac{2}{3} 10^{5}, \frac{2}{3} 10^{5}, \frac{2}{3} 10^{5}, \frac{1}{4} 10^{5}\right), Y_{R}=\left(\frac{1}{8}, 0,0,2.88 \cdot 10^{5}, \frac{16}{3} 10^{3}, \frac{16}{3} 10^{3}, \frac{16}{3} 10^{3}, 2 \cdot 10^{3}\right)$. The results (Figs. 1 and 2) demonstrate the monotonic behaviour of the method as well as its capability of respecting analytically obtained Riemann invariants $\left(p+\rho R_{n n}\right.$ being invariant with respect to the three contact discontinuities associated with $\lambda_{2}, \lambda_{3-6}, \lambda_{7}$ ).

The second case of a symmetrical double shock $\left(Y_{L}=\left(1,100,0,3.7 \cdot 10^{5}, \frac{2}{3} 10^{4}, \frac{2}{3} 10^{4}\right.\right.$, $\left.\frac{2}{3} 10^{4}, \frac{1}{4} 10^{4}\right), Y_{R}=\left(1,-100,0,3.7 \cdot 10^{5}, \frac{2}{3} 10^{4}, \frac{2}{3} 10^{4}, \frac{2}{3} 10^{4}, \frac{1}{4} 10^{4}\right)$ underlines the fact that

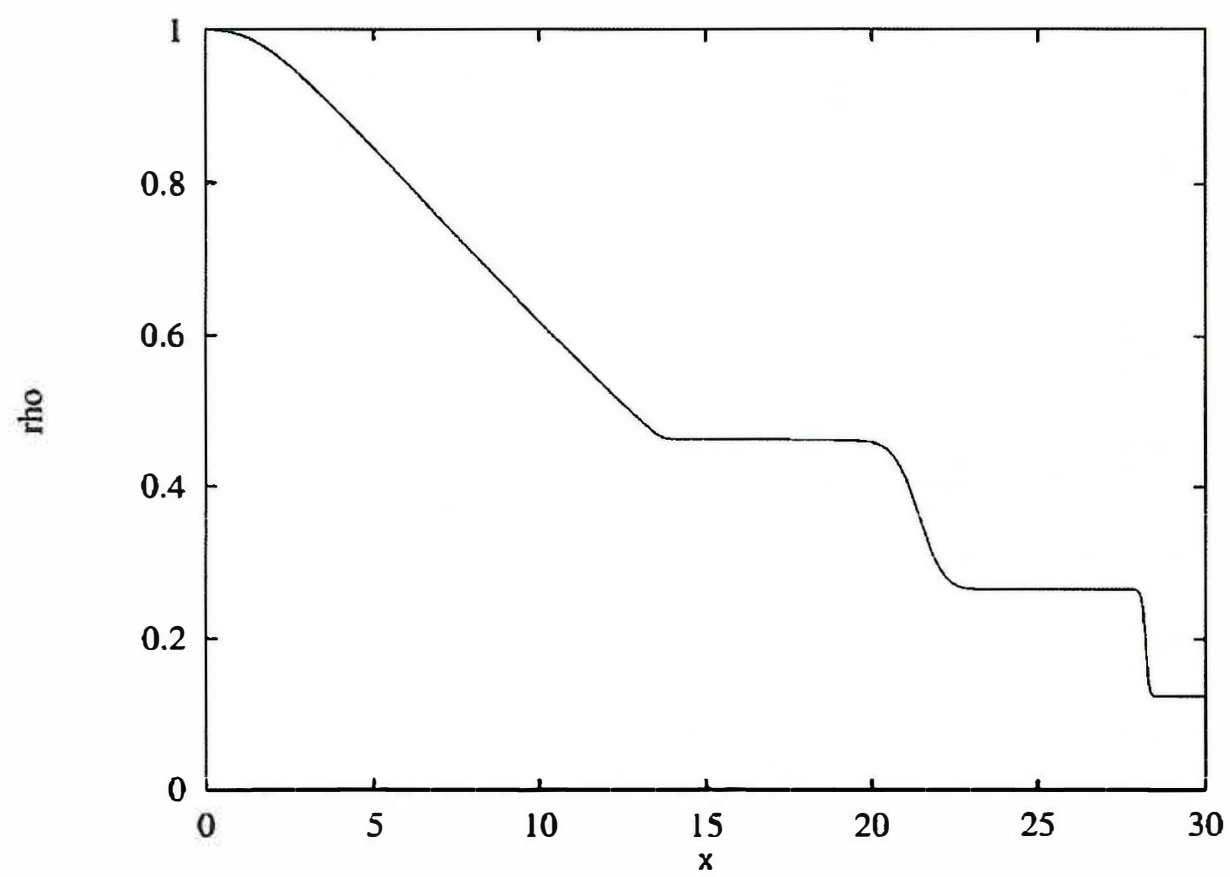

FIG. 1. Turbulent shock tube; distribution of density $\rho$ obtained with the present scheme (RNC). 


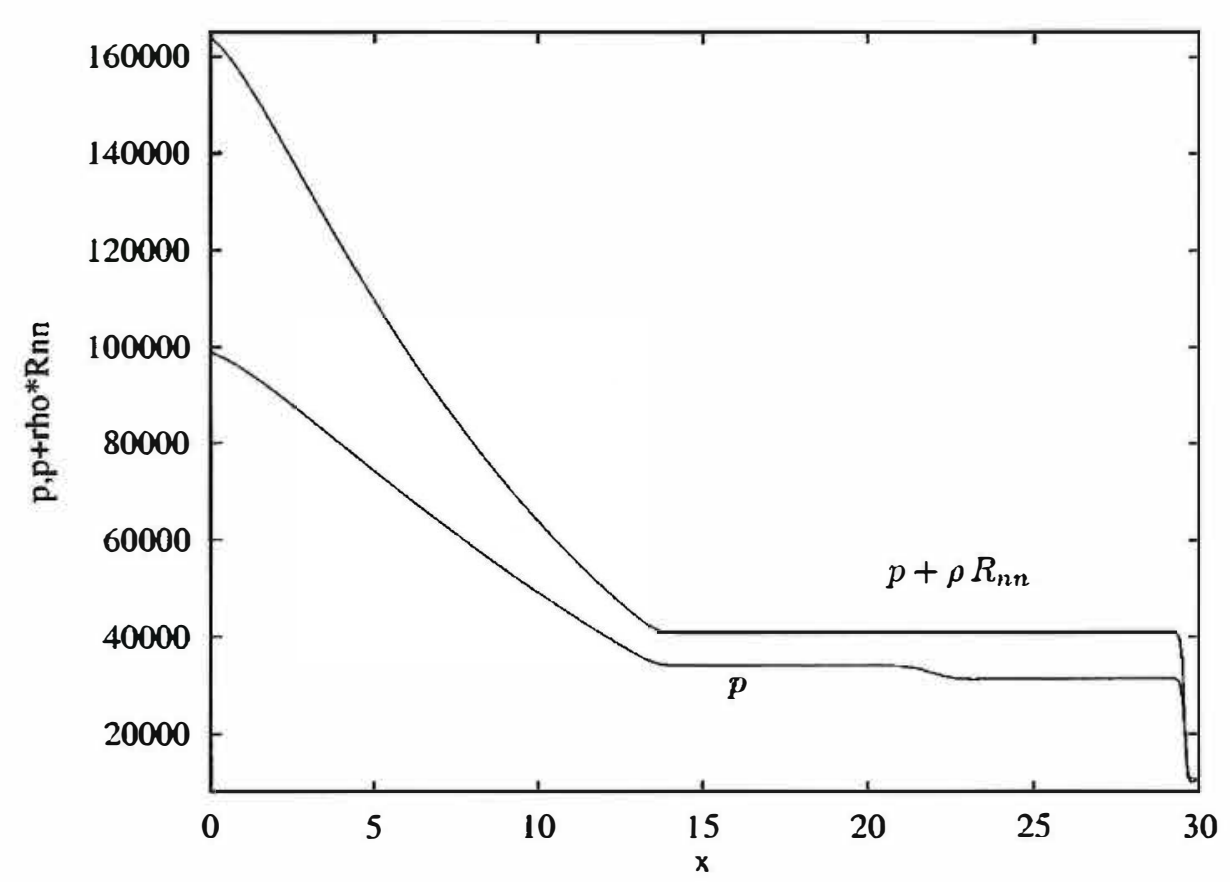

FIG. 2. Turbulent shock tube; distribution of pressure $p$ and total normal stress $p+\rho R_{n n}$ obtained with the scheme RNC, the latter quantity being invariant with respect to the contact discontinuity in the center 3-4-5-6wave).

essentially Euler-based methods - decoupling the turbulent wave system from the aerothermodynamic one- - can lead to spectacular oscillations (Fig. 4). The proposed RNC method, on the other hand, captures adequately the wave propagation, even of very sensitive quantities like the Riemann invariants of the 2- and 7-wave, $U_{t} \pm R_{n \tau} / \sqrt{R_{n n}}$ (Fig. 3).

Detailed information on the analytical solution of the Riemann problem as well as all specific ingredients of the numerical method can be obtained from the authors upon request.

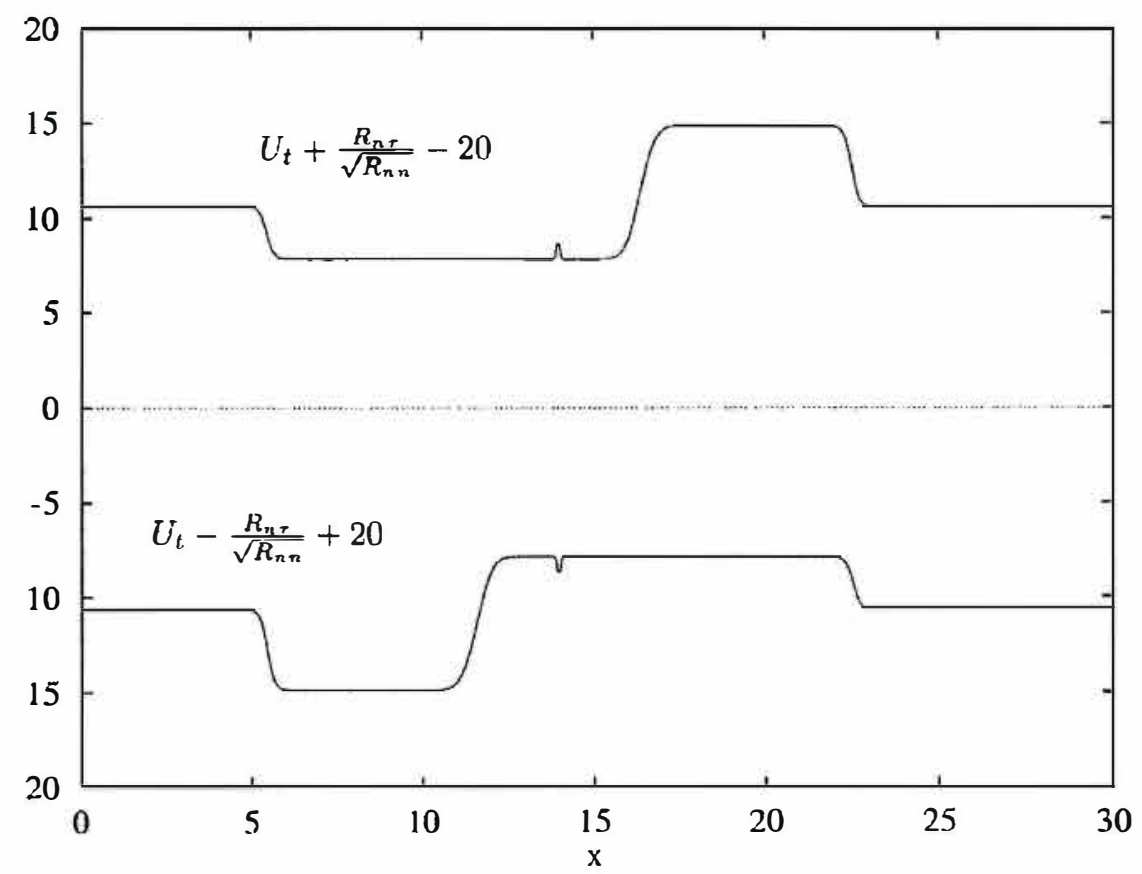

FIG. 3. Symmetrical double shock; distribution of invariants $U_{1} \pm R_{n \tau} / \sqrt{R_{m m}}$ obtained with the present scheme (RNC). 


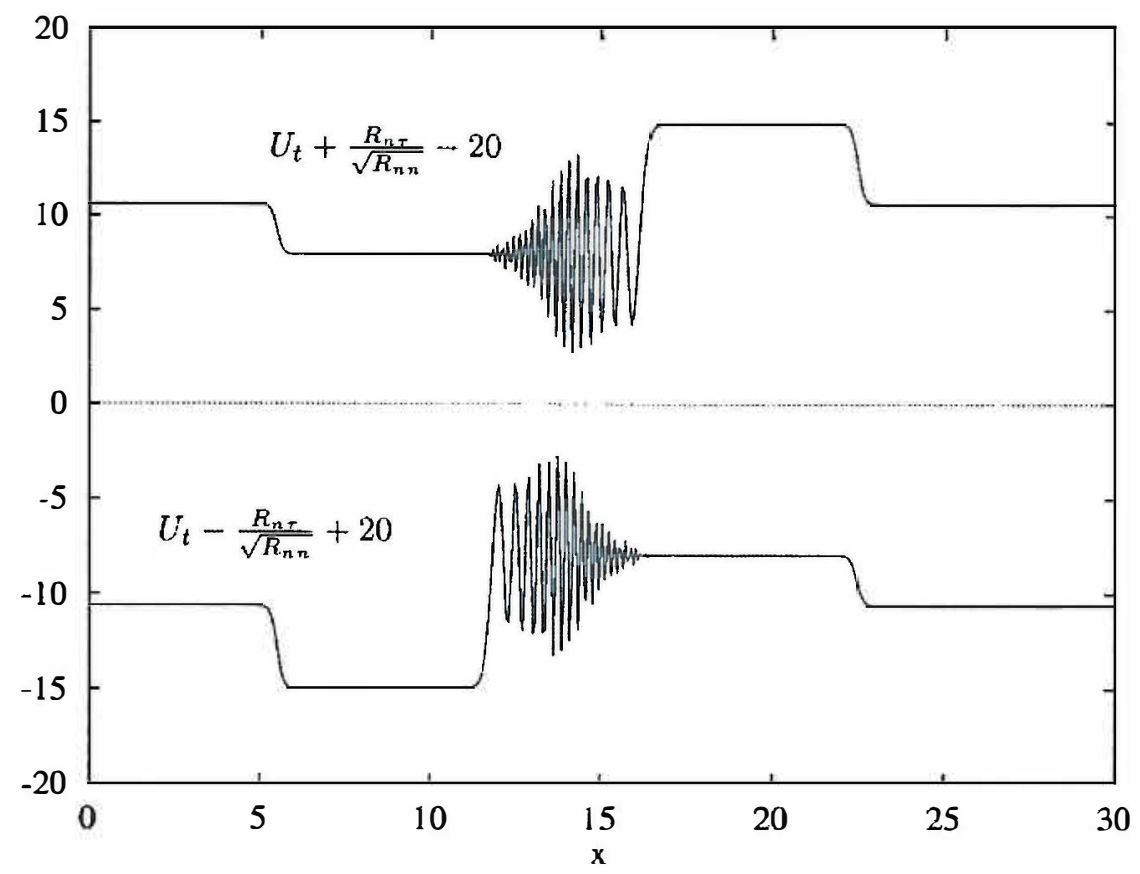

FIG. 4. Symmetrical double shock; distribution of invariants $U_{t} \pm R_{n t} / \sqrt{R_{m}}$ obtained with the "decoupled approach."

\section{REFERENCES}

1. M. Uhlmann, Etude de modèles de fermeture au second ordre et contribution à la résolution numérique des écoulements turbulents compressibles, Ph.D. thesis, Ecole Centrale de Lyon, 1997.

2. C. Berthon, F. Coquel, J.-M. Hérard, and M. Uhlmann, An Approximate Solution of the Riemann Problem for a Realisable Second-Moment Closure, Technical Report HE-41/98/054/A, Electricité de France.

3. A.Forestier, J.-M. Hérard, and X. Louis, Solveur de type Godunov pour simuler les écoulements compressibles, C. R. Acad. Sci. Paris Sér: 1 324, 919 (1997).

4. P. L. Roe, Approximate Riemann solvers, parameter vectors, and difference schemes, J. Comput. Phys. 43 (1981).

5. J. H. Morrison, A Compressible Navier-Stokes Solver with Two-Equation and Reynolds Stress Turbulence Closure Models, Technical Report CR 4440, NASA, 1992.

6. P. Le Floch, Entropy weak solutions to nonlinear hyperbolic systems under nonconservative form, Comm. Partial Differential Equations 13(6), 669 (1988).

7. P. Le Floch and T.-P. Liu, Existence Theory for Nonlinear Hyperbolic Systems in Nonconservative Form, Technical Report 254, Ecole Polytechnique, Centre de Math. App., 1992.

8. J.-M. Hérard, A. Forestier, and X. Louis, A Non Strictly Hyperbolic System to Describe Compressible Turbulence, Technical Report HE-41/94/11/A, Electricité de France, 1994.

9. A. Forestier, J.-M. Hérard, and X. Louis, An investigation of the $k-\varepsilon$ and $k-r$ turbulent compressible models, in ASME FED 224, ASME Fluids Engineering Division Summer Meeting, Hilton Head, SC, August 1995, p. 155.

10. C. Berthon, F. Coquel, J.-M. Hérard, and M. Uhlmann, An Approximate Riemann Solver to Compute Compressible Flows Using Second-Moment Closures, AIAA Paper 97-2069, 13th AIAA CFD Conference, Snowmass, CO, 1997.

11. A. Forestier, J.-M. Hérard, and X. Louis, Exact or approximate Riemann solvers to compute a two-equation turbulent compressible model, in Finite Elements in Fluids (New Trends and Applications, Venezia, Italy, 1995).

12. T. Buffard and J.-M. Hérard, Approximate Riemann solvers to compute turbulent compressible one and two-equation models, in ASME FED 238, ASME Fluids Engineering Division Summer Meeting, San Diego, CA, July 1996, p. 189.

13. L. Combe and J.-M. Hérard, Un schéma volumes finis pour la simulation d'un modèle bi-fluide d'écoulements diphasiques compressibles gaz-solide, Rev. Europ. Eléments Finis 5(2), 197 (1997).

14. G. A. Sod, A survey of several finite difference methods for systems of nonlinear hyperbolic conservation laws, J. Comput. Phys. 27, 1 (1978). 
